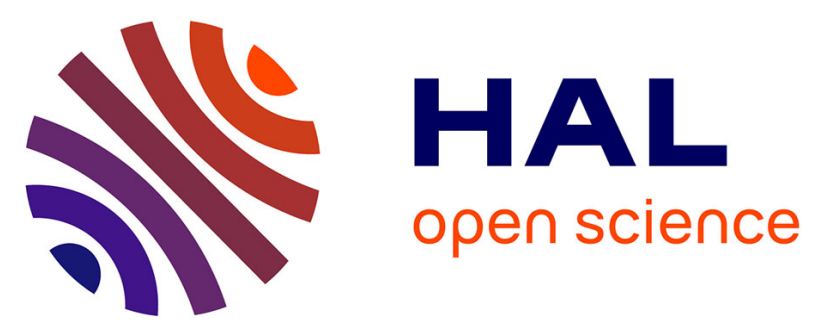

\title{
Saturable absorption optimization of silica protected thin Sb2Te3 layers towards super-resolution applications
}

Charles Moisset, Antoine Bourgade, Julien Lumeau, Fabien Lemarchand, Carine Perrin-Pellegrino, Hassan Akhouayri, Jean-Yves Natoli, Konstantinos Iliopoulos

\section{To cite this version:}

Charles Moisset, Antoine Bourgade, Julien Lumeau, Fabien Lemarchand, Carine Perrin-Pellegrino, et al.. Saturable absorption optimization of silica protected thin Sb2Te3 layers towards super-resolution applications. Optical Materials, 2018, 86, pp.7-11. 10.1016/j.optmat.2018.09.028 . hal-02066437

\section{HAL Id: hal-02066437 https://hal.science/hal-02066437}

Submitted on 13 Mar 2019

HAL is a multi-disciplinary open access archive for the deposit and dissemination of scientific research documents, whether they are published or not. The documents may come from teaching and research institutions in France or abroad, or from public or private research centers.
L'archive ouverte pluridisciplinaire HAL, est destinée au dépôt et à la diffusion de documents scientifiques de niveau recherche, publiés ou non, émanant des établissements d'enseignement et de recherche français ou étrangers, des laboratoires publics ou privés. 


\title{
Saturable absorption optimization of silica protected thin $\mathrm{Sb}_{2} \mathrm{Te}_{3}$ layers towards super-resolution applications
}

Charles Moisset $^{\mathrm{a}}$, Antoine Bourgade ${ }^{\mathrm{a}}$, Julien Lumeau ${ }^{\mathrm{a}}$, Fabien Lemarchand ${ }^{\mathrm{a}}$, Carine Perrin-Pellegrino ${ }^{\mathrm{b}}$, Hassan Akhouayri ${ }^{\mathrm{a}}$, Jean-Yves Natoli ${ }^{\mathrm{a}}$, Konstantinos Iliopoulos ${ }^{\mathrm{a},{ }^{*}}$

${ }^{a}$ Aix Marseille Univ, CNRS, Centrale Marseille, Institut Fresnel, Marseille, France

${ }^{b}$ Aix Marseille Univ, Univ Toulon, CNRS, IM2NP, UMR 7334, Marseille, France

*E-mail address: konstantinos.iliopoulos@fresnel.fr

Keywords: Nonlinear optical response, Nonlinear absorption, Chalcogenides, Z-scan, Super-resolution

\begin{abstract}
$\mathrm{Sb}_{2} \mathrm{Te}_{3}$ thin films are very promising candidates for nonlinear optics and several applications including super-resolution and nano-photoinscription. This work aims to offer a detailed study of the preparation of the thin films and their nonlinear optical properties under nanosecond laser excitation. Thin $\mathrm{Sb}_{2} \mathrm{Te}_{3}$ films have been deposited by the electron beam deposition technique. The films have been protected by a thin silica layer, then annealed in order to enhance their nonlinearities by material crystallization. The annealing has been optimized by simultaneously recording the X-Ray diffraction diagrams. After this optimization, the annealing could be safely performed by heating in an oven. The nonlinear optical properties of the $\mathrm{Sb}_{2} \mathrm{Te}_{3}$ thin films have been studied by means of the Z-scan technique employing $11 \mathrm{~ns}$ laser pulses at $1064 \mathrm{~nm}$ and $532 \mathrm{~nm}$. High nonlinear absorption has been found showing the possibility to employ these materials for super-resolution, mode-locking and other applications.
\end{abstract}





\section{Introduction}

Currently there is a growing interest for optical inscription of nano-objects inside materials. Surpassing the diffraction limit however imposes several difficulties and different methods have been suggested in order to achieve that, as for example X-Ray lithography [1]. However such techniques require complicated experimental procedures and high cost equipment. Recently Stimulated Emission Depletion (STED) has been combined with direct laser writing, providing a high resolution $(55 \mathrm{~nm})$ [2]. In this case a complex experimental setup has been required.

Another way to surpass the diffraction limit is to use the nonlinear absorption and/or the nonlinear refraction $[3,4]$. Both processes can result to a decrease of the size of a focused Gaussian beam by the material itself. In the case of the nonlinear refraction a self-focusing of the material is needed. Concerning the nonlinear absorption, a saturable absorption is required, which provides a decrease of the transmittance by decreasing the laser intensity. In this way the low-intensity part of the beam is absorbed resulting to a decrease of the beam size. The resolution enhancement can be in principle further improved by combining twophoton processes $[5,6]$. This approach can be very promising for a variety of applications including waveguiding, integrated spectroscopy, frequency converting in the nanoscale, as well as optical data storage.

The main difficulty of using the nonlinear optical (NLO) response of materials for super-resolution is the necessity of high optical nonlinearities. Thin films based on the chalcogenide material $\mathrm{Sb}_{2} \mathrm{Te}_{3}$ can be very promising candidates as they can exhibit a very high saturable absorption [3,7]. However an optimization of their structure is necessary in order to achieve the desirable nonlinearities. Few reports exist concerning the NLO response of the $\mathrm{Sb}_{2} \mathrm{Te}_{3}$ material $[3,7,8]$, there is consequently no sufficient understanding of the relation between its structure, the laser excitation parameters and the nonlinear optical response. In 
this work we provide a detailed presentation of $\mathrm{Sb}_{2} \mathrm{Te}_{3}$ thin films deposition and postpreparation, aiming to enhance the optical nonlinearities. Then their NLO response is studied by the Z-scan technique $[9,10]$ both at the IR $(1064 \mathrm{~nm})$ and the visible $(532 \mathrm{~nm})$ parts of the spectrum.

\section{Experimental part}

Firstly, thin $\mathrm{Sb}_{2} \mathrm{Te}_{3}$ films have been deposited on B270 multicomponent silicate glass substrates by the electron beam deposition technique (Bühler SYRUSpro 710), at room temperature, with a rate of $0.5 \mathrm{~nm} / \mathrm{s}$ and using pure $\mathrm{Sb}_{2} \mathrm{Te}_{3}$ glass targets. Two different series of thin films, having different thicknesses have been deposited. The thickness of each set of films has been measured by local removal of the thin film layer and then performing Atomic Force Microscopy measurements. The thicknesses of the two sets of thin films have been found to be $200 \mathrm{~nm}$ and $24 \mathrm{~nm}$ respectively. A relatively high thickness has been chosen for the first set of films in order to provide a significant signal, during the XRD studies and thus a higher accuracy. A set of thinner films (24 nm thickness) has been prepared for the NLO studies in order to increase the compatibility with super resolution applications. This is due to the fact that for Super-Resolution applications steep focusing is required providing short Rayleigh lengths. Moreover a low thickness provides a higher sample transmittance, which is beneficial for applications.

A $10 \mathrm{~nm}$ thick silica layer has been deposited in all cases over the $\mathrm{Sb}_{2} \mathrm{Te}_{3}$, in the same chamber, immediately after the deposition of the latter, in order to avoid critical oxidation of the material during the annealing. Different strategies could be followed in order to avoid oxidation, as for example heating in vacuum or in gas atmosphere $[8,11,12]$. However adding a thin silica layer appeared as a more efficient approach as it can protect the thin films even 
after the annealing. Moreover it can allow laser annealing of the samples under air, which can be useful in several cases. Another advantage of using silica as protecting layer, is its transparency at the VIS-NIR region of the spectrum and its negligible NLO response, compared with chalcogenide glasses [13].

The XRD studies have been carried out with a theta-theta configuration and $\mathrm{CuK} \alpha$ radiation by in-situ annealing. The annealing has been carried out in an Anton Paar chamber under air.

In order to measure the third order nonlinear optical parameters of thin film layers a Zscan setup has been built. The Z-scan technique is based on the measurement of the transmission of a thin sample along the propagation axis of a focused laser beam. Two different detection types are carried out simultaneously. The "open aperture" and the "closed aperture" Z-scans. The former is based on the measurement of the total laser beam, while the latter on the measurement of the central part of the beam passing through a diaphragm. Consequently the "open aperture" can give valuable information concerning the nonlinear absorption of a material. On the contrary the "closed aperture" recordings are containing the contributions of the nonlinear refraction and the nonlinear absorption. In this work the nonlinear refraction has been found to be at least one order of magnitude lower than the nonlinear absorption. Consequently the nonlinear optical response is mainly emanating from the nonlinear absorptive part (imaginary part of the third order nonlinear susceptibility $\operatorname{Im} \chi^{(3)}$ ).

From several "open aperture" Z-scan curves, obtained for different laser energies, the nonlinear optical parameters have been obtained using the procedure detailed elsewhere $[10,14]$. Briefly the nonlinear absorption parameter $(\beta)$ has been determined by means of the following equation:

$$
\mathrm{T}=\frac{1}{\sqrt{\pi}\left(\frac{\beta \mathrm{I}_{0} \mathrm{~L}_{\text {eff }}}{1+\mathrm{z}^{2} / \mathrm{z}_{0}^{2}}\right)} \int_{-\infty}^{\infty} \ln \left[1+\frac{\beta \mathrm{I}_{0} \mathrm{~L}_{\text {eff }}}{1+\mathrm{z}^{2} / \mathrm{z}_{0}^{2}} \exp \left(-\mathrm{t}^{2}\right)\right] \mathrm{dt}
$$


where $\mathrm{I}_{0}$ is the on-axis irradiance at the focus, $\mathrm{L}_{\mathrm{eff}}$ is the effective thickness of the sample defined as $\mathrm{L}_{\mathrm{eff}}=\left(1-\exp \left(-\alpha_{0} \mathrm{~L}\right)\right) / \alpha_{0}$ and $\alpha_{0}$ is the linear absorption coefficient of the sample at the laser excitation wavelength. The $\mathrm{L}_{\mathrm{eff}}$ values used in our data analysis were $9.8 \mathrm{~nm}$ and 14.0 $\mathrm{nm}$ at $532 \mathrm{~nm}$ and $1064 \mathrm{~nm}$ respectively.

Then the imaginary part of the third order nonlinear susceptibility has been determined by means of the following equation:

$$
\operatorname{Im} \chi^{(3)}(\mathrm{esu})=\frac{10^{-7} \mathrm{c}^{2} \mathrm{n}_{0}^{2}}{96 \pi^{2} \omega} \beta(\mathrm{cm} / \mathrm{W})
$$

where $\mathrm{c}$ is the speed of light in $\mathrm{cm} \mathrm{s}^{-1}, \mathrm{n}_{0}$ is the linear refractive index and $\omega$ is the fundamental frequency in cycles per sec.

For the nonlinear optical studies a Nd:YAG laser delivering $11 \mathrm{~ns}$ laser pulses at 1064 $\mathrm{nm}$ and $532 \mathrm{~nm}$ (the latter obtained by frequency doubling), with a $10 \mathrm{~Hz}$ repetition rate has been employed. The laser beam has a Gaussian profile, while the beam waist (corresponding at $1 / \mathrm{e}^{2}$ intensity) has been measured to be $41 \mu \mathrm{m}$ and $39 \mu \mathrm{m}$ for the $1064 \mathrm{~nm}$ and the $532 \mathrm{~nm}$ respectively. During the Z-scan studies, it is of great importance to keep the irradiated area unchanged. In the case of the $\mathrm{Sb}_{2} \mathrm{Te}_{3}$-based thin films studied here, this means that no damage/ deformation of the sample and no modification of the crystallization state shall arise during the measurements. On the contrary low energies do not provide sufficient signal to noise ratios in order to obtain high quality measurements. For this reason special care has been taken in order to assure that the signal to noise ratio has been sufficient, while the transmission of the irradiated area remained unchanged during the measurements. 


\section{Results and discussion}

Due to the deposition process, the fabricated $\mathrm{Sb}_{2} \mathrm{Te}_{3}$ layers are amorphous and enhancing their nonlinearity requires a high degree of crystallization. This is due to the fact that the high saturable absorption efficiency is attributed to a resonant bond weakening with temperature [7]. More specifically the temperature at the center of the irradiation area is higher due to a higher intensity of the Gaussian laser beam, while it is gradually decreasing towards the edge of the beam. This temperature variation modifies the $\mathrm{Sb}_{2} \mathrm{Te}_{3}$ lattice, which in turn alters the resonant bond. Consequently, an initial strengthening of the resonant bond throughout the thin film is necessary, which can be done by aligning the atoms through annealing. This mechanism has been reported to result to a monotonous decrease of the linear absorption coefficient with increasing temperature $\left(\mathrm{d} \alpha / \mathrm{dt}=-5.89 \times 10^{3} \mathrm{~m}^{-1} \mathrm{~K}^{-1}\right)$.

In order to achieve that, firstly, XRD studies radiation have been performed by in-situ annealing of the $200 \mathrm{~nm}$ films. For this reason, the temperature has been gradually increased from $20^{\circ} \mathrm{C}$ up to $350^{\circ} \mathrm{C}$ with a $10^{\circ} \mathrm{C}$ step. A 10 min annealing has been carried out at each temperature. The XRD patterns have been recorded for these temperatures and some representative XRD signals are shown in Figure 1 for the strongest peak of the XRD pattern. The curve corresponding to the as-deposited, amorphous sample is also presented for comparison reasons. A gradual increase of the peaks intensity has been observed between $240^{\circ} \mathrm{C}$ and $300^{\circ} \mathrm{C}$. For temperatures higher than $310^{\circ} \mathrm{C}$ bubble formation has started to appear in the surface of the samples, deteriorating their quality. The optimal temperature found here for the annealing of the $\mathrm{Sb}_{2} \mathrm{Te}_{3}$ films is in very good agreement with previous findings $[15,16]$.

After the temperature optimization, the rest of the as-deposited samples, prepared for the nonlinear optical measurements, have been annealed in an oven. The thin films have been heated at $300^{\circ} \mathrm{C}$ for 24 hours. A long annealing duration has been chosen in order to assure 
that overall crystallization has been achieved. After the annealing, additional XRD studies have been performed for the annealed and the as-deposited thin films (Figure 2). The asdeposited films present no diffraction peaks. On the contrary, the XRD pattern for the annealed sample corresponds very well to $\mathrm{a} \mathrm{Sb}_{2} \mathrm{Te}_{3}$ rhombohedral, crystalline structure. The (OOl) planes are preferentially oriented parallel to the surface in accordance with previous results $[15,17,18]$. The peak appearing at 22.9 degrees is attributed either to an hexagonal Te structure [19] or to a weak presence of $\mathrm{TeO}_{2}$ in the thin film layer [20].

Then, Vis-NIR spectrophotometric studies have been carried out. In particular, the transmission and the reflection have been recorded before and after the annealing for the $24 \mathrm{~nm}$-thick silica protected $\mathrm{Sb}_{2} \mathrm{Te}_{3}$ thin films. Representative curves can be seen in the figure 3. The annealing resulted to a high increase of the reflectivity and a decrease of the transmission. It has to be noted that the $\mathrm{Sb}_{2} \mathrm{Te}_{3}$ bandgap has been reported to be $0.14-0.20 \mathrm{eV}$, which is far from the laser excitation wavelengths employed for the NLO measurements in this work [21,22].

In order to determine the refractive index of $\mathrm{Sb}_{2} \mathrm{Te}_{3}$, we applied a global optimization procedure in the [400-1800nm] range using a single oscillator Drude Modified ForouhiBloomer model. It is one of the optical dispersion models which derives from the KramersKronig integration and it includes several 'physical' parameters like the optical bandgap. 8 variable parameters describing the complex refractive index dispersion are optimized to minimize a cost function defined as the standard deviation between calculated and experimental transmitted data. The optimization procedure is described in detail elsewhere [23], and the real part of the refractive index as a function of the wavelength, is shown in Figure 4. This significant modification of the optical parameters of the $\mathrm{Sb}_{2} \mathrm{Te}_{3}$ thin films shows the importance of the material for photoinscription. 
Then the nonlinear optical response of the thin films has been investigated by means of the Z-scan technique. The nonlinear refraction has been found to be negligible compared with the nonlinear absorption under the same experimental conditions, as mentioned in the experimental part. Representative "open aperture" curves can be seen in Figures 5a and 5b obtained at $1064 \mathrm{~nm}$ and $532 \mathrm{~nm}$ respectively for the $24 \mathrm{~nm}$ thickness, annealed films. In the case of the $1064 \mathrm{~nm}$ irradiation the incident laser energy per pulse has been $200 \mathrm{~nJ}$, corresponding to a peak intensity of $0.68 \mathrm{MW} / \mathrm{cm}^{2}$. In the case of the curve obtained at 532 $\mathrm{nm}$ the incident laser energy per pulse employed was $180 \mathrm{~nJ}$, which resulted to the same peak intensity (due to the slightly different size of the beam waists for the two different wavelengths). The transmission maximum of the "open aperture curves" at the focal plane indicates a saturable absorption character at both wavelengths. It shall be noted that no nonlinearity has been detected in the case of the as-deposited thin films. A plethora of experimental curves at different incident laser energies have been fitted and analyzed following the procedure detailed in the experimental section. In this way the nonlinear absorption parameter $(\beta)$ and the imaginary part of the third order nonlinear susceptibility $\left(\operatorname{Im} \chi^{(3)}\right)$ have been determined and are shown in Table 1 for the two different wavelengths. An increase of the values can be seen in the case of the $532 \mathrm{~nm}$ irradiation. This can be attributed to the higher linear absorption of the sample at $532 \mathrm{~nm}$. More specifically, the linear absorption coefficients of the samples have been found to be $0.09 \mathrm{~nm}^{-1}$ and $0.05 \mathrm{~nm}^{-1}$ at 532 $\mathrm{nm}$ and $1064 \mathrm{~nm}$ respectively, based on the spectroscopic data shown in Figure 3. Indeed, as previously mentioned, the nonlinear optical response of the $\mathrm{Sb}_{2} \mathrm{Te}_{3}$ material under ns laser pulse irradiation is of thermal origin, which can explain the different attributes obtained at the two excitation wavelengths. It has to be noted that the strong nonlinear absorption found here and the multiple beam interference that can arise in the layers can have an impact on the 
determined nonlinear optical values [24, 25]. These aspects are currently studied by our group for the $\mathrm{Sb}_{2} \mathrm{Te}_{3}$ silica protected thin film structures.

The knowledge of the NLO response at the NIR part of the spectrum and a direct comparison of the nonlinearity in the visible and the NIR are of great importance and have been until now, to the best of our knowledge, unexplored. It reveals that although in the NIR the nonlinearity decreases by a factor of 2, the nonlinear optical parameters remain significantly high. This is valuable in terms of Super-Resolution applications. Indeed, many chalcogenide glasses and other materials are mainly transparent in the NIR, so multilayers of different materials, including the $\mathrm{Sb}_{2} \mathrm{Te}_{3}$ can be designed, exhibiting relatively low losses, which is much more difficult in the visible part of the spectrum. Another advantage of employing an IR excitation is that the super resolved inscriptions can be combined with simultaneous detection of the optical nonlinearities of the materials (as for example the second and the third harmonic generation). The latter cannot be carried out easily using visible irradiation, as the nonlinear optical signals are generated at the UV part of the spectrum, which is highly absorbed by many materials.

The nonlinear optical response of the $\mathrm{Sb}_{2} \mathrm{Te}_{3}$ material has not been sufficiently studied in the past. Liu et al have reported a nonlinear absorption value $\beta=-6.63 \times 10^{-2} \mathrm{~m} / \mathrm{W}$ [8]. This value is higher than the values reported in our work. The difference between the obtained values is due to the fact that Liu et al employed $50 \mathrm{~ns}$ duration laser pulses at $632.8 \mathrm{~nm}$ (by modulating a He-Ne laser). This difference of the pulse durations (by a factor of 5) can give rise to the one order of magnitude difference between the determined parameters. Indeed it has been previously found [7] that increasing the pulse duration from 50 ns to 120 ns resulted to a 5-fold increase of the nonlinear absorption, which perfectly explains this discrepancy. In a work by Simpson et al [26] it has been found that Sb-Te thin films do not instantly respond to the incident laser light and that a time duration of approximately $10 \mathrm{~ns}$ is required. The 11 
ns pulse duration employed here allows an efficient activation of the third order nonlinearities within a single laser pulse. This means that excessive heating of the irradiated area, which can result to a faster damaging of the samples, is avoided.

The most important parameter, which shows the possibility to employ a material for super-resolved inscription/storage is the transmittance maximum of the normalized "open aperture" Z-scan curves (see Figure 3). In our work a value of 1.06-1.07 has been obtained, while a similar value has been reported by Liu et al (approximately 1.10) [8]. In another work by the same group, carried out using $100 \mathrm{~ns}$ duration pulses at $405 \mathrm{~nm}$ [3], a 1.10 transmittance maximum has been found. Ma et al [27] have shown that a Si nonlinear mask can form approximatively $80 \mathrm{~nm}$ nanostructures in an AgInSbTe thin film, having a transmittance maximum of about 1.010, much lower than the values reported here. The possibility to use the saturable absorption for local modification of the linear and nonlinear optical properties of materials in order to fabricate optical devices in the nanoscale has not been yet demonstrated. Our current research is focusing in optimising the NLO response of thin film multilayers towards this direction.

\section{Conclusions}

In this work we have optimised the crystallisation state of thin $\mathrm{Sb}_{2} \mathrm{Te}_{3}$ films in terms of their third order nonlinear optical response. The crystallisation has been confirmed by means of XRD measurements. The nonlinear optical response has been studied by means of the Zscan technique, using nanosecond laser pulses at the visible and the NIR parts of the spectrum. In all cases high nonlinear absorption parameters have been found (of the order of $\left.10^{-3} \mathrm{~m} / \mathrm{W}\right)$. The prepared samples can be very promising for photonic applications related with photoinscription of nano-photonic components. 



\section{Acknowledgements}

This work was supported by the Region PACA (Project: APEX 2017 NANOFAB) 


\section{References:}

[1] F. Huo, Z. Zheng, G. Zheng, L.R. Giam, H. Zhang, C.A. Mirkin, Polymer Pen Lithography, Science 321 (2008) 1658-1660. doi:10.1126/science.1162193.

[2] R. Wollhofen, J. Katzmann, C. Hrelescu, J. Jacak, T.A. Klar, $120 \mathrm{~nm}$ resolution and 55 $\mathrm{nm}$ structure size in STED-lithography, Opt. Express. 21 (2013) 10831-10840. doi:10.1364/OE.21.010831.

[3] J. Wei, S. Liu, Y. Geng, Y. Wang, X. Li, Y. Wu, A. Dun, Nano-optical information storage induced by the nonlinear saturable absorption effect, Nanoscale 3 (2011) 32333237. doi:10.1039/c1nr10395d.

[4] J. Wei, H. Yan, Laser beam induced nanoscale spot through nonlinear "thick" samples: A multi-layer thin lens self-focusing model, J. Appl. Phys. 116 (2014) 063107. doi:10.1063/1.4892871.

[5] K. Iliopoulos, O. Krupka, D. Gindre, M. Sallé, Reversible Two-Photon Optical Data Storage in Coumarin-Based Copolymers, J. Am. Chem. Soc. 132 (2010) 14343-14345. doi:10.1021/ja1047285.

[6] M.C. Spiridon, K. Iliopoulos, F.A. Jerca, V.V. Jerca, D.M. Vuluga, D.S. Vasilescu, D. Gindre, B. Sahraoui, Novel pendant azobenzene/polymer systems for second harmonic generation and optical data storage, Dyes Pigments 114 (2015) 24-32. doi:10.1016/j.dyepig.2014.10.010.

[7] S. Liu, J. Wei, F. Gan, Nonlinear absorption of Sb-based phase change materials due to the weakening of the resonant bond, Appl. Phys. Lett. 100 (2012) 111903. doi:10.1063/1.3693156.

[8] J. Liu, S. Liu, J. Wei, Origin of the giant optical nonlinearity of $\mathrm{Sb}_{2} \mathrm{Te}_{3}$ phase change materials, Appl. Phys. Lett. 97 (2010) 261903. doi:10.1063/1.3530428. 
[9] K. Iliopoulos, D. Potamianos, E. Kakkava, P. Aloukos, I. Orfanos, S. Couris, Ultrafast third order nonlinearities of organic solvents, Opt. Express. 23 (2015) 24171-24176. doi:10.1364/OE.23.024171.

[10] M. Sheik-Bahae, A.A. Said, T.-H. Wei, D.J. Hagan, E.W. Van Stryland, Sensitive measurement of optical nonlinearities using a single beam, Quantum Electron. IEEE J. Of. 26 (1990) 760-769. doi:10.1109/3.53394.

[11] S. Fujimori, S. Yagi, H. Yamazaki, N. Funakoshi, Crystallization process of Sb-Te alloy films for optical storage, J. Appl. Phys. 64 (1988) 1000-1004. doi:10.1063/1.341908.

[12] J.-W. Park, S.H. Baek, T.D. Kang, H. Lee, Y.-S. Kang, T.-Y. Lee, D.-S. Suh, K.J. Kim, C.K. Kim, Y.H. Khang, J.L.F. Da Silva, S.-H. Wei, Optical properties of (GeTe, $\mathrm{Sb}_{2} \mathrm{Te}_{3}$ ) pseudobinary thin films studied with spectroscopic ellipsometry, Appl. Phys. Lett. 93 (2008) 021914. doi:10.1063/1.2959818.

[13] T. Olivier, F. Billard, H. Akhouayri, Nanosecond Z-scan measurements of the nonlinear refractive index of fused silica, Opt. Express. 12 (2004) 1377-1382. doi:10.1364/OPEX.12.001377.

[14] P. Aloukos, K. Iliopoulos, S. Couris, D.M. Guldi, C. Sooambar, A. Mateo-Alonso, P.G. Nagaswaran, D. Bonifazi, M. Prato, Photophysics and transient nonlinear optical response of donor-[60]fullerene hybrids, J. Mater. Chem. 21 (2011) 2524-2534. doi:10.1039/c0jm03520c.

[15] Q. Wang, B. Liu, Y. Xia, Y. Zheng, R. Huo, M. Zhu, S. Song, S. Lv, Y. Cheng, Z. Song, S. Feng, Characterization of Cr-doped $\mathrm{Sb}_{2} \mathrm{Te}_{3}$ films and their application to phasechange memory, Phys. Status Solidi RRL - Rapid Res. Lett. 9 (2015) 470-474. doi:10.1002/pssr.201510214. 
[16] Y. Zhang, J. Feng, Z. Zhang, B. Cai, Y. Lin, T. Tang, B. Chen, Characteristics of Sidoped $\mathrm{Sb}_{2} \mathrm{Te}_{3}$ thin films for phase-change random access memory, Appl. Surf. Sci. 254 (2008) 5602-5606. doi:10.1016/j.apsusc.2008.03.006.

[17] Y. Yin, H. Sone, S. Hosaka, Characterization of nitrogen-doped $\mathrm{Sb}_{2} \mathrm{Te}_{3}$ films and their application to phase-change memory, J. Appl. Phys. 102 (2007) 064503. doi:10.1063/1.2778737.

[18] T. Liu, H. Deng, H. Cao, W. Zhou, J. Zhang, J. Liu, P. Yang, J. Chu, Structural, optical and electrical properties of $\mathrm{Sb}_{2} \mathrm{Te}_{3}$ films prepared by pulsed laser deposition, $\mathrm{J}$. Cryst. Growth. 416 (2015) 78-81. doi:10.1016/j.jcrysgro.2015.01.022.

[19] PDF 00-036-1452 (ICDD, 1986).

[20] B. Lv, S. Hu, W. Li, X. Di, L. Feng, J. Zhang, L. Wu, Y. Cai, B. Li, Z. Lei, Preparation and Characterization of $\mathrm{Sb}_{2} \mathrm{Te}_{3}$ Thin Films by Coevaporation, Int. J. Photoenergy. 2010 (2010) 1-4. doi:10.1155/2010/476589.

[21] J.-W. Park, S.H. Eom, H. Lee, J.L.F. Da Silva, Y.-S. Kang, T.-Y. Lee, Y.H. Khang, Optical properties of pseudobinary GeTe, $\mathrm{Ge}_{2} \mathrm{Sb}_{2} \mathrm{Te}_{5}, \mathrm{GeSb}_{2} \mathrm{Te}_{4}, \mathrm{GeSb}_{4} \mathrm{Te}_{7}$, and $\mathrm{Sb}_{2} \mathrm{Te}_{3}$ from ellipsometry and density functional theory, Phys. Rev. B. 80 (2009) 115209. doi:10.1103/PhysRevB.80.115209.

[22] J.K. Olson, H. Li, T. Ju, J.M. Viner, P.C. Taylor, Optical properties of amorphous GeTe, $\mathrm{Sb}_{2} \mathrm{Te}_{3}$, and $\mathrm{Ge}_{2} \mathrm{Sb}_{2} \mathrm{Te}_{5}$ : The role of oxygen, J. Appl. Phys. 99 (2006) 103508. doi:10.1063/1.2194327.

[23] L. Gao, F. Lemarchand, M. Lequime, Comparison of different dispersion models for single layer optical thin film index determination, Thin Solid Films. 520 (2011) 501-509. doi:10.1016/j.tsf.2011.07.028.

[24] J. Wei, M. Xiao, A Z-scan model for optical nonlinear nanometric films, J. Opt. A: Pure Appl. Opt. 10 (2008) 115102. 
[25] I. Mirza, D. McCloskey, W. J. Blau, J. G. Lunney, Mechanism of large optical nonlinearity in gold nanoparticle films, Opt. Lett. 43 (2018) 1455.

[26] R.E. Simpson, P. Fons, X. Wang, A.V. Kolobov, T. Fukaya, J. Tominaga, Nonmelting super-resolution near-field apertures in Sb-Te alloys, Appl. Phys. Lett. 97 (2010) 161906. doi:10.1063/1.3502593.

[27] X. Ma, J. Wei, Nanoscale lithography with visible light: optical nonlinear saturable absorption effect induced nanobump pattern structures, Nanoscale. 3 (2011) 1489-1492. doi:10.1039/c0nr00888e. 


\section{Figure Captions:}

Fig. 1: Enhancement of the (0015) XRD diffracted peak of the $\mathrm{Sb}_{2} \mathrm{Te}_{3}$ thin film as a function of the annealing temperature.

Fig. 2: XRD pattern of an annealed $\left(300^{\circ} \mathrm{C}\right)$ and an as-deposited sample.

Fig. 3: Transmission and reflectivity spectroscopic measurements before and after the annealing of the thin layers.

Fig.4: Refractive index of the $\mathrm{Sb}_{2} \mathrm{Te}_{3}$ thin films as a function of the wavelength, obtained by a modified Forouhi-Bloomer model.

Fig. 5: "Open aperture" Z-scans recorded at (a) $11 \mathrm{~ns}, 1064 \mathrm{~nm}, 200 \mathrm{~nJ}$ and at (b) $11 \mathrm{~ns}, 532 \mathrm{~nm}, 180$ $\mathrm{nJ}$ for the $\mathrm{Sb}_{2} \mathrm{Te}_{3}$ annealed thin films. 